\title{
A comparative study of cortico-cancellous iliac bone graft with or without the combination of vascularized greater trochanter flap for the management of femoral head osteonecrosis: a minimum 6 years follow-up
}

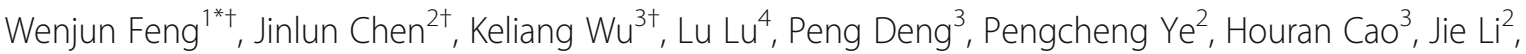
Jianchun Zeng ${ }^{2}, \mathrm{Ke} \mathrm{Jie}^{1}$, Xinyu $\mathrm{Qi}^{3}$ and Yirong Zeng ${ }^{2^{*}}$

\begin{abstract}
Background: To compare the mid-long-term clinical and radiological outcomes between a combination of corticocancellous iliac bone graft with vascularized greater trochanter flap (Group A) and isolate iliac bone graft (Group B) in the treatment of Osteonecrosis of the Femoral Head (ONFH).

Methods: From January 2006 to December 2012, 123 patients (135 hips) who underwent abovementioned hippreserving surgeries were included for analysis. Clinical outcomes were assessed based on Harris Hip Score (HHS) System and The Western Ontario and McMaster University Index (WOMAC) scores between the preoperative and the last follow-up. A series of postoperative $X$-rays were compared to preoperative images for radiological evaluation
\end{abstract}

Results: The HHS in Group A and B were enhanced from $50.57 \pm 3.39$ to $87.60 \pm 4.15$ and from $50.24 \pm 3.30$ to 85 . $18 \pm 6.45$, respectively, which both showed significance between preoperative and postoperative latest follow-up $(p<0.001)$. Group A revealed better improvement in terms of HHS $(p=0.017)$. The WOMAC total, postoperative stiffness, difficulty subscale scores in Group A showed better outcomes when compared to Group B $(p<0.01)$, while pain improvement between these two groups revealed no significance $(p=0.402)$. Besides, Group A suggested better necrotic region repair $(p=0.020)$, but no femoral head collapse difference in terms of Association Research Circulation Osseous classification change was found ( $p>0.05$ ).

Conclusions: A combination of cortico-cancellous iliac bone graft and concurrent vascularized greater trochanter flap with the lateral femoral circumflex transverse branch has been proved can obtain better functional and radiological results than isolate iliac bone grafting, which is attributed to blood reconstruction of the femoral head.

Keywords: Osteonecrosis of the femoral head, Vascularized greater trochanter flap, Cortico-cancellous iliac bone graft, Hip-preserving, Outcomes comparison

\footnotetext{
* Correspondence: foreverarsene@126.cm; 13711456292@163.com

'Wenjun FENG, Jinlun Chen and Keliang Wu contributed equally to this work.

'Guangzhou University of Chinese Medicine, Jichang Road 16\#, District Baiyun, Guangzhou, Guangdong, China

${ }^{2}$ The First Affiliated Hospital of Guangzhou University of Chinese Medicine,

Jichang Road 16\#, District Baiyun, Guangzhou, Guangdong, China

Full list of author information is available at the end of the article
}

(c) The Author(s). 2019 Open Access This article is distributed under the terms of the Creative Commons Attribution 4.0 International License (http://creativecommons.org/licenses/by/4.0/), which permits unrestricted use, distribution, and reproduction in any medium, provided you give appropriate credit to the original author(s) and the source, provide a link to the Creative Commons license, and indicate if changes were made. The Creative Commons Public Domain Dedication waiver (http://creativecommons.org/publicdomain/zero/1.0/) applies to the data made available in this article, unless otherwise stated. 


\section{Background}

Osteonecrosis of the femoral head (ONFH) is a common debilitating and disabling condition, which is characterized as blood supply impairment of the femoral head, bone marrow and osteocytes death, subchondral bone collapse, articular cartilage degeneration and ultimate secondary osteoarthritis $[1,2]$. It mainly affects adults in their thirty and forty decades of life [3], with an estimated number over 20,000,000 worldwide today [4] and morbidity incidence ranged from $8.9 / 100,000$ [5] to 28.9/100,000 [6]. Though alcohol intake [7], corticosteroid use [8], posttraumatic [9], bone marrow fat embolisms [10], hypercoagulation [11] and endothelial dysfunction [12] have been identified as its risk factors, the underlying etiology and pathogenesis is still not completely clear [13], which makes it difficult to predispose the development and advancement in gene and molecular level.

Once ONFH is confirmed, the intervention shall initiate immediately. Mont MA et al. [14] found that when treatment delayed, 70\% cases will suffer progressive collapse in about 3 to 4 years according to the natural course of ONFH. Though Total Hip Arthroplasty (THA) has been proved to be an effective procedure in the treatment of ready collapse late stage ONFH $[15,16]$ with a mean $90 \%$ survivorship at 20 years in most implants [17], it poses great challenge on younger patients when considering prosthesis early loosen [18], revisions [19] and infections [20] Therefore, other hip-preserving surgeries aimed to delay and/or prevent THA conversion as long as possible in these young patients are needed. The goal of hip-preserving surgeries is to restore disordered bone metabolism and maintain stable structure support. Various surgeries have been proposed to improve necrosis bone repair and prevent or postpone progressive collapse, such as core decompression [21], proximal femur rotational osteotomy [22], vascularized [23] or non-vascularized [24] bone grafting, artificial biomaterials impaction [25], bone grafting combining with bone morphogenetic protein [26], and autologous bone marrow aspirate transplantation [27]. For these precollapse ONFH cases, bone grafting can not only provide mechanical support, but also improve necrotic region biological environment when necrotic tissues were thoroughly removed [28]. With regard to the bone grafting surgery, vascularized and non-vascularized options are available to perform mainly depended on surgeon preference. Alderdge et al. [29] discovered that revascularization of the necrotic region can stimulate osteoinductive progenitor cells invasion and promote bone revitalizing. Once blood supply is restored or reconstructed, vital bone can gradually creeping substitute the necrotic tissues and a relative normal subchondral plate is regained.
However, to our knowledge, no consensus has been reached concerning the superiority of mid-long-term efficacy in postcollapse ONFH cases between these two types of bone grafting techniques. Thus, we conducted a retrospective comparative study between cortico-cancellous iliac bone graft alone and in combination with concurrent vascularized greater trochanter flap based on the lateral femoral circumflex artery transverse branch, for the treatment of ONFH in Association Research Circulation Osseuse (ARCO) stage III at a minimum 6 years follow-up. As we have seen, no prior published studies have compared the clinical and radiological outcomes between these two surgeries. We asked the following questions: (1) What are the mid-long-term clinical and radiological outcomes of the abovementioned two techniques? (2) Which technique shows superiority in terms of improvement on Harris Hip Score (HSS), The Western Ontario and McMaster University Index (WOMAC) total and subscale scores, extent of femoral head collapse and necrotic region repairment? (3) What is the survivorship of each technique when consider THA conversion as the endpoints?

\section{Methods}

Patients who underwent hip-preserving surgeries were retrospectively reviewed at the First Affiliated Hospital of Guangzhou University of Traditional Chinese Medicine from January 2006 to December 2012. This study was approved by the Ethics Committee of Guangzhou University of Traditional Chinese Medicine and it complied with the Declaration of Helsinki. Patients who presented in ARCO stage III with age between 18 years and 45 years and underwent previous described two surgical procedures were considered as the inclusion criteria. Candidates who underwent a combination of iliac bone and vascularized greater trochanter flap with lateral femoral circumflex artery transverse branch and isolate cortico-cancellous iliac bone graft and were divided into Group A and Group B, respectively. The exclusion criteria consisted of previous hip invasion surgeries (such as core decompression, stem cell injection, endovascular intervention), tumor, metabolic bone disease, hip infections, history of blood vessel structure and/or function disorder, unable to follow postoperative training programs and incapable of understanding instructions due to mental health deficiency.

One hundred and twenty seven patients (139 hips) were recruited in the current study. In Group A, 1 patients (1 hip) died after postoperative 10 months attributed to unrelated surgical cause, and 1 patient (1 hip) was eliminated for further analysis because of corticosteroids pulse therapy due to primary disease relapse. There was one patient (1 hip) in each group was lost follow-up. Therefore, 123 patients (135 hips, 97.1\%) were enrolled for finally assessment. There were 51 men (55 hips) and 
72 women (80 hips), and patients completed regular instructed revisit in the out-patient department. The demographics data consisted of number of patients (hips), age (at the time of surgery), sex, Body Mass Index (BMI), affected sides, etiologies in both groups were presented in Table 1.

\section{Surgical procedure}

All surgeries were performed by one same senior surgeon. The complete procedure has been described in previous study [30] and was categorized as 3steps. In briefly, in the first step, a modified Smith-Peterson approach was used for exposure. The lateral femoral circumflex artery transverse branch was identified and separated from surrounded soft tissues carefully, followed by the greater trochanter flap was chiseled with arc-shaped osteotome along the pedicle parts. In the second step, an opening window-like approach access to the necrotic region was obtained. The necrotic tissues were thoroughly removed and the hardening boundary was destructed via a 1.5-mm Kirschner wire drilling. In the third step, a rectangular cortico-cancellous iliac bone graft was harvested according to the necrotic size and was cut into half to fit the necrotic space. The remaining gap was filled with allogeneic cancellous bone tightly impaction grafting and the prepared vascularzied greater trochanter flap was implanted. The femoral head was shaped more congruent and reduced. For patients in Group B, the surgical procedure was the same as Group A except for the vascularized greater trochanter flap preparation and implantation. Patients were not allowed weight-bearing at the first 6 weeks followed by partial weight-bearing till the 6 th postoperative month. Full weight-bearing was allowed after the 6 th postoperative month.

\section{Outcome evaluation}

Outcome evaluation was performed by two independent investigators. All patients follow-up was scheduled at 3, 6, 12 months and yearly thereafter. HHS and WOMAC (pain, stiffness and difficulty subscales) scores was used for clinical evaluation. A series of anteroposterior and frog lateral X-rays of bilateral hips at preoperative and each follow-up were used for radiographic evaluation. Femoral head morphology and necrotic region repair process were the primary objectives of radiological evaluation. We defined reduced or disappeared necrotic cystic lesions without osteoarthritis (OA) as improved, and reduced or stabled necrotic cystic region with no or slight $\mathrm{OA}$ as stabilized, and enlarged necrotic region with apparent OA as aggravated. It was defined as clinical failures of these two surgeries when subsequent THA was indicated. Besides, the complications were also recorded.

\section{Statistical analysis}

All statistical analysis was performed using SPSS Statistical software (Version 18.0, IBM Cooperation, USA). Distributions of quantitative variables were expressed as means $( \pm \mathrm{SD})$ or by median and interquartile range. For intra- group analysis, the Wilcoxon Test was used to compare the preoperative and the last postoperative HSS and WOMAC scores in these two groups, while the Mann-Whitney U Test was used for inter-groups preoperative baseline and postoperative difference analysis. Qualitative variables were summarized as count and percentage and compared with Fisher's exact test. A $P$-value less than 0.05 were considered to be statistical significance.

Table 1 Comparison of baseline characteristics of Group A and B

\begin{tabular}{|c|c|c|c|}
\hline Characteristics & Group A & Group B & $P$ value \\
\hline No. of patients(Hips) & $77(84)$ & $46(51)$ & \\
\hline Age (years; mean $\pm S D$, [range]) & $33.2 \pm 5.7(18-45)$ & $32.8 \pm 5.0(18-45)$ & 0.724 \\
\hline Sex(female/male) & $46 / 31$ & $26 / 20$ & 0.850 \\
\hline $\mathrm{BMI}\left(\mathrm{kg} / \mathrm{m}^{2}\right)$ & $22.0 \pm 1.2(19.5-25.4)$ & $22.3 \pm 1.3(19.8-24.9)$ & 0.335 \\
\hline $\mathrm{F}-\mathrm{U}$ time (years; mean $\pm \mathrm{SD}$, [range]) & $9.7 \pm 1.4(6-12)$ & $9.8 \pm 1.3(7-12)$ & 0.789 \\
\hline Affected hips (Right/Left) ${ }^{a}$ & $48 / 36$ & $27 / 24$ & 0.722 \\
\hline \multicolumn{4}{|l|}{ Risk factors } \\
\hline Alcohol & 24 & 15 & $>0.999$ \\
\hline Corticosteroid & 36 & 20 & 0.852 \\
\hline Idiopathic & 17 & 11 & 0.827 \\
\hline \multicolumn{4}{|l|}{ ARCO stage } \\
\hline IIIA & 29 & 18 & 0.537 \\
\hline$\| \mathrm{B}$ & 41 & 21 & \\
\hline IIIC & 14 & 12 & \\
\hline
\end{tabular}

BMI Body Mass Index, F-U Follow-Up, ARCO Association Research Circulation Osseous. ${ }^{\text {a }}$ patients had bilateral involved hips in Group A, while Group B had 5 patients with bilateral affected hips. $P<0.05$ indicates significance 
Table 2 HHS, WOMAC total and subscale scores in both groups

\begin{tabular}{|c|c|c|c|c|c|c|c|c|c|}
\hline \multirow{3}{*}{$\begin{array}{l}\text { Parameters } \\
\text { Pre-HHS }\end{array}$} & \multicolumn{4}{|c|}{ Group A } & \multicolumn{4}{|c|}{ Group B } & \multirow{3}{*}{$\begin{array}{l}p \text { value for } \\
\text { intergroup }\end{array}$} \\
\hline & \multicolumn{3}{|c|}{ Mean \pm SD } & \multirow{2}{*}{$\begin{array}{l}p \text { value for intragroup } \\
<0.001^{*}\end{array}$} & \multicolumn{3}{|c|}{ Mean \pm SD } & \multirow{2}{*}{$\begin{array}{l}p \text { value for intragroup } \\
<0.001^{*}\end{array}$} & \\
\hline & 50.57 & \pm & 3.38 & & 50.24 & \pm & 3.30 & & \\
\hline Post-HHS & 87.60 & \pm & 4.15 & & 85.18 & \pm & 6.45 & & \\
\hline Pre-WOMAC & 90.52 & \pm & 8.22 & $<0.001^{*}$ & 87.00 & \pm & 7.98 & $<0.001^{*}$ & $<0.001^{*}$ \\
\hline Post-WOMAC & 36.75 & \pm & 6.70 & & 39.90 & \pm & 5.55 & & \\
\hline Pre-pain & 11.68 & \pm & 2.37 & $<0.001^{*}$ & 11.33 & \pm & 2.73 & $<0.001^{*}$ & 0.402 \\
\hline Post-pain & 1.96 & \pm & 1.28 & & 1.88 & \pm & 1.29 & & \\
\hline Pre-stiffness & 11.17 & \pm & 2.16 & $<0.001^{*}$ & 12.63 & \pm & 1.44 & $<0.001^{*}$ & $<0.001^{*}$ \\
\hline Post-stiffness & 2.99 & \pm & 2.16 & & 2.90 & \pm & 1.32 & & \\
\hline Pre-difficulty & 68.12 & \pm & 5.05 & $<0.001^{*}$ & 68.53 & \pm & 4.30 & $<0.001^{*}$ & $0.008^{*}$ \\
\hline Post-difficulty & 32.63 & \pm & 4.14 & & 35.29 & \pm & 3.00 & & \\
\hline
\end{tabular}

HHS Harris Hip Score, WOMAC Western Ontario and McMaster University Index. Wilcoxon test was used for preoperative and the last postoperative intra-groups comparison, while Mann-Whitney $U$ test was used for intergroup and delta difference comparison

\section{Results}

The preoperative and the latest follow-up HHS, WOMAC total scores and subscale scores in both groups were presented in Table 2. The HHS in both groups revealed significant statistical difference when compared to preoperative levels $(p<0.001)$. Besides, Group A revealed more rate of improvement than Group B in the aspect of HHS difference ( $\triangle$ HHS equal to the latest follow-up HHS minus preoperative scores, $p=0.017)$. The last postoperative WOMAC total and subscale scores (pain, stiffness and difficulty) showed significant improvements when compared to the preoperative baseline in both groups ( $p$ values were all less than 0.001). Group A showed more superior results than Group B in terms of total, subgroup stiffness and difficulty enhancement $(p<0.01)$, while the difference of WOMAC subscale pain scores between these two groups revealed no significance $(p=0.402)$.

ARCO classification system was used for evaluation of the extent of femoral head collapse, which was summarized in Table 3. In terms of femoral head collapse, both groups showed significant improvement in the latest postoperative follow-up when compared to preoperative femoral head shape ( $p=0.046$ and 0.040 , respectively). However, no significance was presented between these two groups from the aspects of femoral head collapse $(n=27$ and 14, respectively, $p>0.05)$. The improved, stabilized and aggravated cases in Group A were 19, 38, 27. While in Group B, 23 cases were improved, 14 cases were stabilized, and 14 cases were aggravated (Fig. 1 and Fig. 2). Group A revealed better repair capability $(p=0.020$, Table 4$)$.

THA conversion was defined as failure of these two surgeries. 6 hips $(7.14 \%, 6 / 84)$ in Group A accepted THA at a mean follow-up of 6.8 years (range, 6-8 years). Among the conversion hips, 3 hip was in ARCO stage IIIB and 3 hips were in ARCO stage IIIC at the time of surgery. There were 11 hips $(21.6 \%, 11 / 51)$ had THA conversion Group B with an average follow-up of 6.5 years (range, 6-8 years). 1 of these hips had ARCO stage IIIA, 4 hips had ARCO stage IIIB, and the other 6 hips had ARCO stage IIIC. Group A showed better survivorship than Group B $(P=0.030)$.

One superficial wound infection occurred in Group A and healed after extended antibiotics administration. 2 patients complained prolonged greater trochanter donor pain, which finally complete relieved through physical

Table 3 Comparison of radiological outcomes in terms of the extent of femoral head collapse between preoperative and the last postoperative follow-up in Group A and B

\begin{tabular}{|c|c|c|c|c|c|c|c|}
\hline \multirow{2}{*}{$\begin{array}{l}\text { ARCO } \\
\text { classification }\end{array}$} & \multicolumn{2}{|l|}{ Group A } & \multirow{2}{*}{$\begin{array}{l}P \\
\text { value }\end{array}$} & \multicolumn{2}{|l|}{ Group B } & \multirow{2}{*}{$\begin{array}{l}P \\
\text { value }\end{array}$} & \multirow{2}{*}{$\begin{array}{l}P \text { value for } \\
\text { improvement a }\end{array}$} \\
\hline & preoperative & postoperative & & preoperative & postoperative & & \\
\hline IIIA & 29 & 45 & 0.046 & 18 & 31 & 0.040 & 0.568 \\
\hline IIIB & 41 & 30 & & 21 & 14 & & \\
\hline IIIC & 14 & 9 & & 12 & 6 & & \\
\hline
\end{tabular}

ARCO Association Research Circulation Osseous. a The comparison between Group A and B in terms of ARCO classification improvement was analyzed by Chi-square test. In Group A, 4 hips in ARCO IIIA were aggravated, 17 hips was stabilized, 8 hips were improved. 13 hips in ARCO IIIB were aggravated, 19 hips was stabilized, 9 hips were improved. 10 hips in ARCO IIIC were aggravated, 2 hips was stabilized, 2 hips were improved. In Group B, 3 hips in ARCO IIIA were aggravated, 7 hips was stabilized, 8 hips were improved. 5 hips in ARCO IIIB were aggravated, 4 hips was stabilized, 12 hips were improved. 6 hips in ARCO IIIC were aggravated, 3 hips was stabilized, 3 hips were improved 


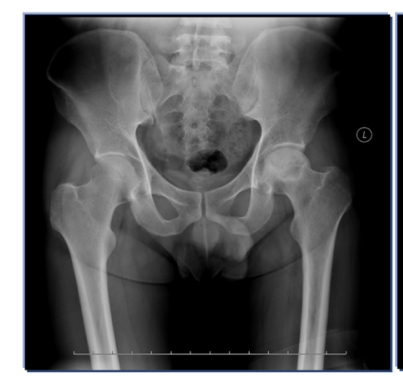

a

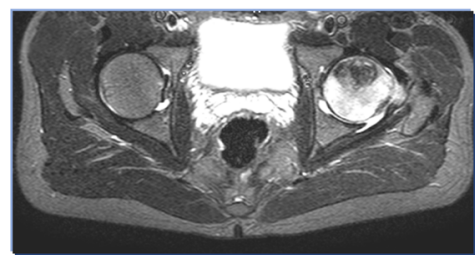

c

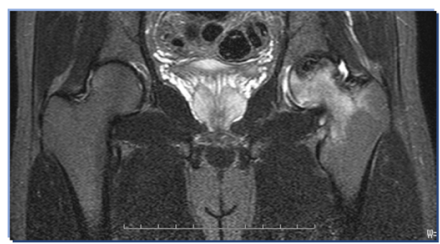

e

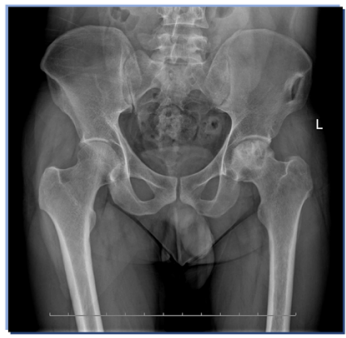

g

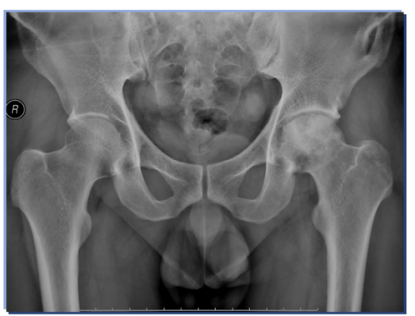

i

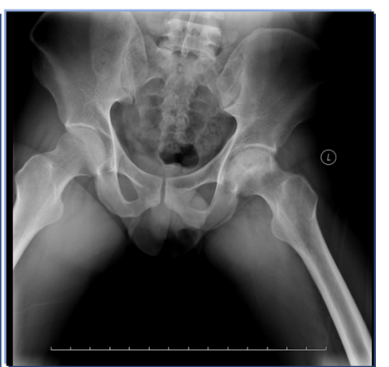

$\mathbf{b}$

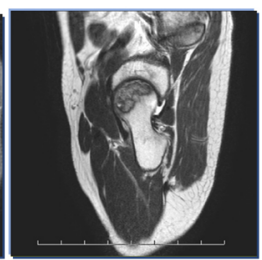

d

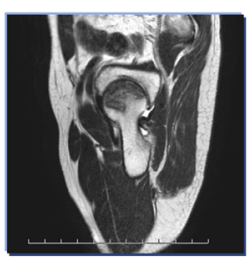

f

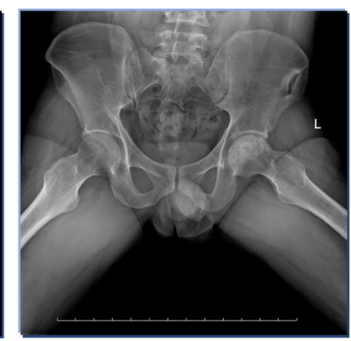

h

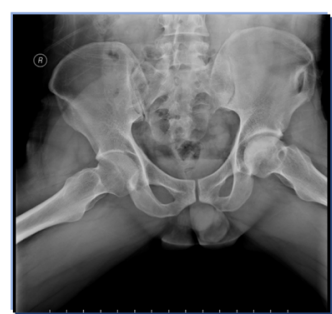

j
Fig. $1(\mathbf{a}, \mathbf{b})$ Anteroposterior and frog lateral X-rays of bilateral hips showed that left hips were in ARCO stage IIIC. (c, d, e, f) preoperative $\mathrm{MRI}$ images showed left hip was involved serious $\mathrm{ONFH}$. $(\mathbf{g}, \mathbf{h})$ the immediate radiographs followed by free iliac flap grafting combining with vascularized greater trochanter implantation of left hip were shown. (i, j) intact joint space was achieved with matched femoral head morphology at10 years postoperatively, and the left hip was successfully preserved therapy and oral analgesics administration. No greater trochanter or pelvic fracture occurred. Each group had 2 patients with numbness and hypoesthesia in the lateral parts of thigh, which resolved with time.

\section{Discussion}

$\mathrm{ONFH}$ is a commonly seen intractable condition, which mainly affects young and middle-aged individuals and makes the treatment very challenging. Though THA has been known as one of the most successful and creative techniques in twentieth century, it does put young patients into great risks of implant early loosen, infections and revisions [18-20]. The primary purpose of hip-preserving surgeries is to delay and/or prevent THA conversion. Various hip-preserving surgical options have been proposed, however, the most-effective treatment is still under great controversies [31].

The principle of hip-preserving surgeries for prevention of femoral head collapse and promotion of necrotic region repairment consisted of complete necrotic bone removal, trabecular bone reconstruction, hip biomechanics restoration as well as femoral head blood supply recovery [32]. Necrotic thoroughly debridement combining with bone grafting shows the potential of preventing femoral head collapse through reconstructs mechanical support. In 1930, Phemister was the first surgeon that using non-vascularized fibular bone grafting in the treatment of ONFH, which based on the theory that the implanted bone would not only provided mechanical support, but also could be the scaffold for progenitor cells adhesion and new bone creeping substitution [33]. Many new techniques had been documented since then. Trousdale RT [34] found that vascularized bone grafting showed more superior results than non-vascularized bone grafting, which was further confirmed by Kim [35], Mastusaki $\mathrm{H}$ [36], Hasegawa Y [37] and so on. The underlying theory might attribute that blood supply reconstruction would improve circulating stem cells and growth factors delivery, which would increase necrotic region new vital bone formation and promote implanted bone healing [38]. Since the advantages of vascularized bone grafting were introduced, numerous of new options have been described, such as the vascularized greater trochanteric flap, free vascularized fibular graft, iliac crest vascularized graft. Though vascularized bone grafting of all types have been reported to be effective, results from each center were varying. Consequently, new modifications of these techniques are needed.

The vascularized greater trochanter flap grafting is not commonly employed among the abovementioned options [30, 39], it did significant improve HHS and SF-36 scores in postcollapse ONFH patients, and the THA conversion rate at a mean 8 years follow-up was $11.8 \%$ (23/195). Zhao $\mathrm{D}$ et al. [40] conducted an anatomic study and found that 


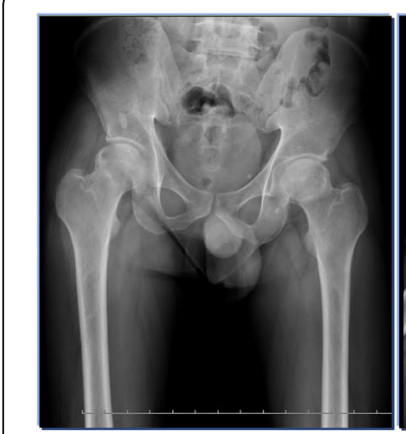

a

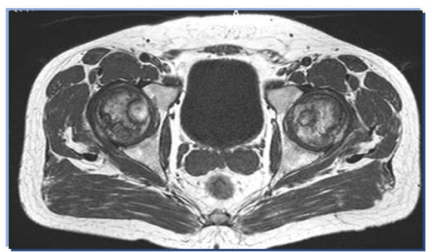

c

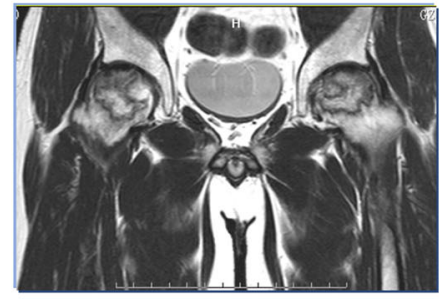

e

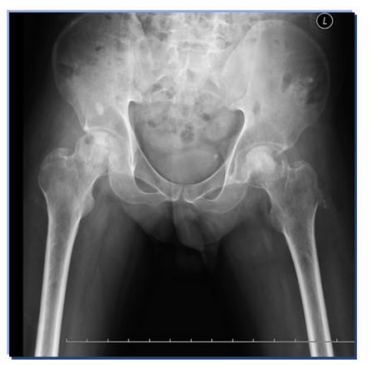

g

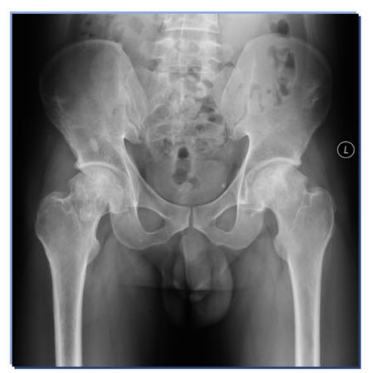

i

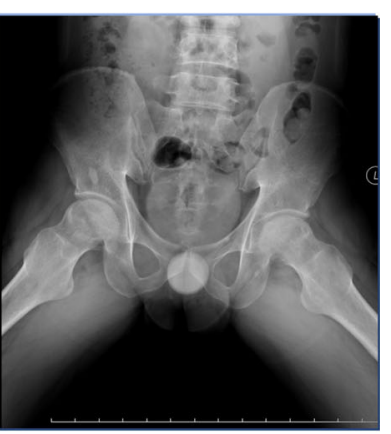

b

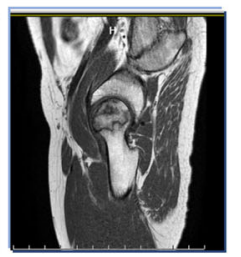

d

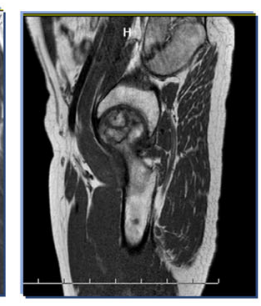

f

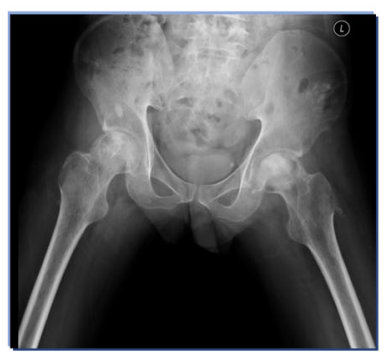

h

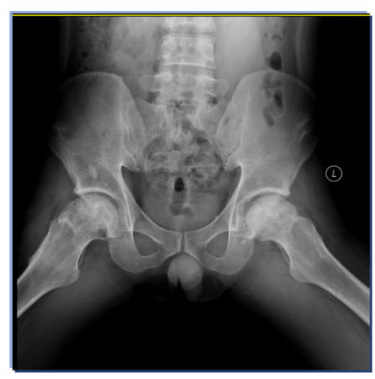

j
Fig. 2 (a, b) anteroposterior and frog lateral X-rays of bilateral hips showed that both hips were involved with ONFH. 2 (c, d, e, f) preoperative $\mathrm{MRI}$ revealed that both involved hips were in ARCO stage IIIC. $(\mathbf{g}, \mathbf{h})$ the immediate radiographs after isolate free iliac bone grafting were presented. $(\mathbf{i}, \mathbf{j})$ the congruent femoral head shape was presented without secondary osteoarthritis at 7 years postoperatively

the outer diameter of lateral femoral circumflex artery transverse branch was $2.5 \pm 0.8 \mathrm{~mm}$ with a sufficient length of $3.5 \pm 0.8 \mathrm{~mm}$, which made it less damage during surgery. The vascularized greater trochanter owned reliable and abundant blood supply. He used the method to treat 32 ONFH patients in Ficat stage II-III, discovered that the clinical success rate was $90.6 \%$ and radiographic success rate was $87.5 \%$. To us known, a comparative study to detect the efficacy between isolate free iliac bone flap with or without concurrent vascularized greater trochanter grafting with femoral circumflex transverse branch has not been documented so far.

In our study, we found that patients obtained very good improvement of HSS at an average 9.7 years follow-up in both Group A and B, which suggested that both techniques showed efficacy in the treatment of ONFH. The good-excellent rate (defined as HHS $\geq 80$ ) in Group A and B was $87.0 \%(73 / 87)$ and $70.6 \%(36 / 51)$, respectively. The Group A showed better HHS improvements, which might be attributed to more efficient repair response due to vascularized greater trochanter flap implantation, though more deep evident studies were needed. In terms of Patient-Reported Outcomes (PROMs) evaluation, all patients in both groups achieved pain relief. However, patients in Group A obtained more improvements in the aspects of and stiffness and daily quality difficulty. We concluded that the implantation of the vital lateral femoral circumflex transverse branch played a crucial role in the necrotic bone repair, implanted bone revascularization and biomechanical stability restoration, especially in the first postoperative year. Though both groups had significant case number change of ARCO subtypes, Group A showed no superior radiological performance than Group B, which might be accounted to small samples in both groups. Further studies concerning digital subtraction angiography, PECT/CT and Magnetic Resonance angiography might provide more firmed evidence regarding the vascularity of implanted lateral femoral circumflex artery transverse branch [41]. The postoperative survivorship at an

Table 4 Comparison of radiological outcomes from the aspect of necrotic region repair between Group A and B

\begin{tabular}{llll}
\hline $\begin{array}{l}\text { Postoperative necrotic } \\
\text { region repair }\end{array}$ & Group A & Group B & $P$ \\
\hline Improved & 19 & 23 & 0.020 \\
Stabilized & 38 & 14 & \\
Aggravated & 27 & 14 & \\
\hline
\end{tabular}


average 9.7 years follow-up between these two groups did not have significance $(92.8 \%$ vs $78.4 \%)$, but both groups showed comparable hip-preserving success. We considered that complete necrotic bone removal, free iliac bone flap sufficient support, allogeneic cancellous bone tight impaction grafting and vital blood circulation of lateral femoral circumflex artery transverse branch pedicled with greater trochanter as the key point to obtain long-term success. 2 patients complained persistent pain in Group A, which, in our opinion, might be attributed to the decrease of resistance to tensile stress oriented from surrounding muscles due the greater trochanter integrity destruction.

The current study has several limitations. First, it was a case-cohort retrospective comparative study. The case number of both groups is relatively small. Though the mean follow-up time in both groups is near 9.7 years, the number of follow-up time beyond 10 years in the study and control group was 25 hips $(29.8 \%, 25 / 84)$ and 12 hips $(23.5 \%, 12 / 51)$, respectively. Our study showed that both hip-preserving techniques can obtain good efficacy and prevent or delay THA conversion. However, we need a randomization study, larger patient samples and longer follow-up time to reduce the bias and validate the outcomes. Second, a lack of postoperative computerized tomographic (CT) scans and MRI evaluation, which can assess the bony microstructure change and cartilage condition. Although a series of postoperative X-rays can provide enough message regarding the necrotic region repairment, extent of femoral head collapse, hip joint space and osteoarthritis appearance, a more comprehensive imaging evaluation might help to make a better objective estimation, especially for cartilage status assessment. Third, we did not assess the relationship between the size and location of necrotic lesion and postoperative clinical and radiological outcomes. Univariate and multivariate liner correlation studies might be beneficial to distinguish risk factors. Regardless of the limitations, we recommended the combination of cortico-cancellous iliac bone graft and vascularized greater trochanter flap grafting with the lateral femoral circumflex artery transverse branch in the treatment of ONFH in ARCO stage III. It is extremely important to make a systematic review of current available techniques to conclude a consensus of indications, contradictions, proper surgical interventions in different ARCO stages for purpose of better outcomes and more consistent results.

\section{Conclusions}

For ONFH in ARCO stage III, both hip-preserving techniques showed good results in terms of hip function preservation. However, a combination of cortico-cancellous iliac bone graft and concurrent vascularized greater trochanter flap with the lateral femoral circumflex transverse branch has been proved can obtain better functional and radiological results.

\section{Abbreviations}

ARCO: Association Research Circulation Osseous; BMI: Body Mass Index; HHS: Harris Hip Score; ONFH: Osteonecrosis of the Femoral Head; PROMs: Patient-Reported Outcomes; THA: Total Hip Arthroplasty; WOMAC: The Western Ontario and McMaster University Index

\section{Acknowledgements}

One of the correspondence authors (Wenjun FENG) want to show heartedly thanks to his wife Yajun Li, who provided much help for form production and grammar expression.

\section{Funding \\ This work was supported by High-Level University Construction Project of Guangzhou University of Chinese Medicine(A1-AFD018171Z11068) and the Science Fund of Guangdong Traditional Chinese Medical Bureau (20171088) in the form of covering the consultation fees of data statistical analysis. Yirong Zeng received scientific funding from High-Level University Construction Project of Guangzhou University of Chinese Medicine and the grant number A1-AFD018171Z11068.}

\section{Availability of data and materials}

The datasets used and/or analyzed during the current study are not publicly available due to feasibility but are available from the corresponding author on reasonable request.

\section{Author's contributions}

$Y Z$ and WF designed the study. And all surgeries was performed by $Y Z$. WF, $\mathrm{JC}$ and KW completed the draft of the manuscript. LL was responsible of the data analysis. PD, PY, HC, JL, JZ, KJ, and XQ contributed to data collection and outcomes evaluation. All co-authors were involved in the revision of the manuscript and approved the final proof.

\section{Ethics approval and consent to participate}

The retrospective study was approved by the Ethics and Academy Committee of The First Affiliated Hospital of Guangzhou University of Chinese Medicine (Grant Number [2017]107). All patients were informed the surgical and rehabilitation details and written consent of data application for future clinical studies was obtained preoperatively.

Consent for publication

Not applicable.

\section{Competing interests}

The authors declare that they have no competing interests.

\section{Publisher's Note}

Springer Nature remains neutral with regard to jurisdictional claims in published maps and institutional affiliations.

\section{Author details}

'Guangzhou University of Chinese Medicine, Jichang Road 16\#, District Baiyun, Guangzhou, Guangdong, China. ${ }^{2}$ The First Affiliated Hospital of Guangzhou University of Chinese Medicine, Jichang Road 16\#, District Baiyun, Guangzhou, Guangdong, China. ${ }^{3}$ Guangzhou University of Chinese Medicine, Jichang Road 12\#, District Baiyun, Guangzhou, Guangdong, China. ${ }^{4}$ The First Affiliated Hospital of Guangzhou University of Chinese Medicine, Linnan Medical Research Center of Guangzhou University of Chinese Medicine, Jichang Road 16\#, District Baiyun, Guangzhou, Guangdong, China.

Received: 13 November 2018 Accepted: 3 May 2019

Published online: 22 June 2019

References

1. Mont MA, Hungerford DS. Non-traumatic avascular necrosis of the femoral head. J Bone Joint Surg Am. 1995;77:459-74.

2. Steinberg ME, Hayken GD, Steinberg DR. A quantitative system for staging avascular necrosis. J Bone Joint Surg Br. 1995;73:34-41.

3. Banerjee S, Issa K, Pivec R, Kapadia BH, Khanuja HS, Mont MA. Osteonecrosis of the hip. treatment options and outcomes Orthop Clin North Am. 2013; 44:463-76. 
4. Liberman JR, Engstrom SM, Meneghini RM, SooHoo NF. Which factors influence preservation of the osteonecrotic femoral head? Clin Orthop Relat Res. 2012;470:525-34.

5. Fukushima W, Fujioka M, Kuto T, Tamakoshi A, Nagai M, Hirota Y. Nationwide epidemiologic survey of idiopathic osteonecrosis of the femoral head. Clin Orthop Relat Res. 2010:468:2715-24.

6. Kang JS, Park S, Song JH, Jung YY, Cho MR, Rhyu KH. Prevalence of osteonecrosis of the femoral head. a nationwide epidemiologic analysis in Korea J Arthroplasty. 2009;21:1178-83.

7. Yoon BH, Kim TY, Shin IS, Lee HY, Lee YJ, Koo KH. Alcohol intake and the risk osteonecrosis of the femoral head in Japanese populations: a doseresponse meta-analysis of case-control studies. Clin Rheumatol. 2017;36(11): 2517:2524.

8. Kubo T, Ueshima K, Saito M, Ishida M, Arai Y, Fujiwara H. Clinical and basic research on steroid-induced osteonecrosis of the femoral head in Japan. J Orthop Sci. 2016;21(4):407-13.

9. Sen RK, Tripathy SK, Gill SS, Verma N, Singh P, Radotra BD. Prediction of posttraumatic femoral head osteonecrosis by quantitative intraosseous aspirate and core biopsy analysis: a prospective study. Acta Orthop Belg. 2010;76(4):486-92.

10. Seamon J, Keller T, Saleh J, Cui Q. The pathogenesis of nontraumatic osteonecrosis. Arthritis. 2012; 2012: 601763.

11. Moya-Angeler J, Gianakos AL, Villa JC, Ni A, Lane JM. Current concepts on osteonecrosis of the femoral head. World J Orthop. 2015;6(8):601-18.

12. Mont MA, Cherian JJ, Sierra RJ, Jones LC, Liberman JR. Nontraumatic osteonecrosis of the femoral head: where do we stand today? A ten-year update J Bone Joint Surg Am. 2015;97(19):1604-27.

13. Issa K, Pivec R, Kapadia BH, Banerjee S, Mont MA. Osteonecrosis of the femoral head: the total hip replacement solution. Bone Joint J. 2013;95-B: 46-50.

14. Mont MA, Jones LC, Hungerford DS. Nontraumatic osteonecrosis of the femoral head: ten years later. J Bone Joint Surg Am. 2016;88(5):1117-32.

15. Capone A, Bienati F, Torchia S, Podda D, Maronqiu. Short stem total hip arthroplasty for osteonecrosis of the femoral head in patients 60 years or younger: a 3- to 10- year follow-up study. BMC Musculoskelet Disord 2017 18(1): 301.

16. Hernigou P, Ooignard A, Nogier A, Manicom O. Fate of very small asymptomatic stage-I osteonecrosis lesions of the hip. J Bone Joint Surg Am. 2004:86:2589-93.

17. Swarup I, Shields M, Mayer EN, Hendow CJ, Burlet JC, Figgie MP. Outcomes after total hip arthroplasty in young patients with osteonecrosis of the hip. Hip Int. 2017;27(3):286-92.

18. Adelani MA, Keeney JA, Palisch A, Flowler SA, Clohisy JC. Has total hip arthroplasty in patients 30 years or younger improved? A systematic review. Clin Orthop Relat Res. 2013;471(8):2595-601.

19. Rajaee SS, Campbell JC, Mirocha J, Paiement GD. Increasing burden of total hio arthroplasty revisions in patients between 45 and 64 years of age. J Bone Joint Surg Am. 2018;100(6):449-58.

20. Garvin KL, Miller RE, Gilbert TM, White AM, Lyden ER. Late reinfection may recur more than 5 years after reimplantation of THA and TKA: analysis of pathogen factors. Clin Orthop Relat Res. 2018;476(2):345-52.

21. Razik F, Alexopoulos AS, El-Osta B, Connolly MJ, Brown A, Hassan S, Ravikumar K. Time to internal fixation of femoral neck fractures in patients under sixty years-dose this matter in the development of osteonecrosis of femoral head? Int Orthop. 2012:36:2127-31.

22. Fuchs B, Knothe U, Hertel R, Ganz R. Femoral osteotomy and iliac graft vascularization for femoral head osteonecrosis. Clin Orthop Relat Res. 2003; 412:84-93.

23. Berend KR, Gunneson EE, Urbaniak JR. Free vascularized fibular grafting for the treatment of postcollapse osteonecrosis of the femoral head. J Bone Joint Surg Am. 2003;85:987-93.

24. Nelson LM, Clark CR. Efficacy of phemister bone grafting in non-traumatic aseptic necrosis of the femoral head. J Arthroplast. 1993;8:253-8.

25. Malizos KN, Papasoulis E, Dailiana ZH, Papatheodorou LK, Varitimidis SE. Early results of a novel technique using multiple small tantalum pegs for the treatment of osteonecrosis of the femoral head: a case series involving 26 hips. J Bone Joint Surg Br. 2012;94(2):173-8

26. Papanagiotou M, Malizos KN, Vlychou M, Dailiana ZH. Autologous (nonvascularised) fibular grafting with recombinant bone morphogenetic protein-7 for the treatment of femoral head osteonecrosis: preliminary report. Bone Joint J. 2014 Jan;96-B(1):31-5.
27. Sen RK, Tripathy SK, Aggarwal S, Marwaha N, Sharma RR, Khandelwal N. Early results of core decompression and autologous bone marrow mononuclear cells instillation in femoral head osteonecrosis. A randomized control study J Arthroplasty. 2012;27:679-86.

28. Wood MB. Free vascularized fibular grafting: 25 years' experience: tips, techniques, and pearls. Orthop Clin North Am. 2007:38:1-12.

29. Aldridge JM 3rd, Urbaniak JR. Vascularized fibular grafting for osteonecrosis of the femoral head with unusual indications. Clin Orthop Relat Res. 2008; 466:1117-24.

30. Zeng Y, He S, Feng W, Li F, Li J, Jian L, Zeng J, Fan Y. Vascularized greater trochanter bone graft, combined free iliac flap and impaction bone grafting for osteonecrosis of the femoral head. Int Orthop. 2013;37(3):391-8.

31. Korompilias AV, Beris AE, Lykissas MG, Kostas-Agnantis IP, Soucacos PN. Femoral head osteonecrosis: why choose free vascularized fubula grafting. Microsurgery. 2011:31:223-8

32. Zhao D, Xie H, Xu Y, Wang Y, Yu A, Liu Y, Wang A, He W, Wang X, Li Z, Sun W, Tian S, Wang B, Liu B. Management of osteonecrosis of the femoral head with pedicled iliac bone flap transfer. A multicenter study of 2190 patients. Microsurgery. 2017;37(8):896-901.

33. Phemister DB. Treatment of the necrotic head of the femur in adults. J Bone Joint Surg. 1943;31(1):55-66.

34. Trousdale RT. Vascularized free fibular graft vs core decompression. Orthopedics. 1997;20(4):359.

35. Kim SY, Kim YG, Kim PT, Ihn JC, Cho BC, Koo KH. Vascularized compared with nonvascularized fibular grafts for large osteonecrosis lesions of the femoral head. J Bone Joint Surg Am. 2005;87(9):2012-8.

36. Matsusaki H, Noguchi M, Kawakami T, Tani T. Use of vascularized pedicle iliac bone graft combined with transtrochanteric rotational osteotomy in the treatment of avascular necrosis of the femoral head. Arch Orthop Trauma Surg. 2005;125(2):95-101.

37. Hasegawa Y, Iwata H, Torii IT, Kawamoto K, Iwasada S. Vascularized pedicle bone-grafting for non-traumatic avascular necrosis of the femoral head. A 5to11-year follow-up. Arch Orthop Trauma Surg. 1997;116(5):251-8.

38. Pavlocic V, Dolinar D, Arnez Z. Femoral head necrosis treatment with vascularized iliac crest. Int Orthop. 1999:23(3):50-153.

39. Zhao D, Wang B, Guo L, Yang L, Tian F. Will a vascularized greater trochanter graft preserve the necrotic femoral head? Clin Orthop Relat Res. 2010;468(5):1316-24.

40. Zhao D, Zhang Y, Xu C. Applied anatomy of greater trochanter boneperiosteum flap pedicled with transversal and middle gluteal muscle branches of lateral circumflex artery. Zhongguo Lin Chuang Jie Pou Xue Za Zhi. 2005;23:234-6.

41. Cao L, Guo C, Chen J, Chen Z, Yan Z. Free vascularized fibular grafting improves vascularity compared with core decompression in femoral head osteonecrosis: a randomized clinical trial. Clin Orthop Relat Res. 2017;475: 2230-40.

Ready to submit your research? Choose BMC and benefit from:

- fast, convenient online submission

- thorough peer review by experienced researchers in your field

- rapid publication on acceptance

- support for research data, including large and complex data types

- gold Open Access which fosters wider collaboration and increased citations

- maximum visibility for your research: over $100 \mathrm{M}$ website views per year

At $\mathrm{BMC}$, research is always in progress.

Learn more biomedcentral.com/submissions 